\title{
Os vários mundos da saúde
}

BASTOS, F. I.

\section{Saúde em Questáo.}

Rio de Janeiro: Claro Enigma / Fiocruz, 2012. 110 p.

I ${ }^{1}$ Claudia Cristina de Aguiar Pereira, 2 Carla Jorge Machado |

${ }^{1}$ Pesquisadora da Escola Nacional de Saúde Pública (ENSP/Fiocruz). Endereço eletrônico: pereirac.claudia@gmail.com

${ }^{2}$ Professora da Faculdade de Medicina da Universidade Federal de Minas Gerais (UFMG). Endereço eletrônico: carlajmachado@gmail.com

Publicado em 2011, o livro Saúde em Questão, editado pela Claro Enigma em parceria com a Editora Fiocruz, faz parte da nova coleção de ciências da Fundação Oswaldo Cruz, que já conta com um volume anterior: Biodiversidade em questão. O autor da obra, Francisco Inácio Bastos, também publicou mais de 200 artigos em periódicos, além de outros livros e capítulos de livros. Em Saúde em questão, o escritor aborda áreas correlacionadas, mas distintas, com desenvoltura. Através de uma exposição clara, o pesquisador estabelece com leveza os parâmetros para que se compreendam a vida e a saúde.

O livro se apresenta em sete capítulos, além de duas seções adicionais. Após explicitar a necessidade de conceituar a saúde e a vida, no primeiro capítulo, percorre um caminho lógico do que é "muito pequeno" em vista do ser humano (átomos e moléculas) para o "muito maior" (o planeta Terra, do ponto de vista do indivíduo), dos capítulos segundo ao sexto. O capítulo sétimo, didaticamente, retoma a questão inicial: "Afinal, o que é a saúde?” As duas últimas seçôes do livro (Sugestôes de atividades e Sugestôes de leitura) convidam o leitor a perceber, em primeiro lugar, as diversas dimensōes da vida e da saúde de forma prática. Em segundo lugar, aprofundar-se em temas tratados no livro por meio de outras obras.

O primeiro capítulo ("O que é a saúde”) reflete sobre o que é a vida e sobre a falta de consenso em defini-la, exemplificando esta falta de unanimidade por meio dos debates que existem sobre o que é "vida natural" e "vida artificial". 
O autor faz uma anologia desta dificuldade de definição com a dificuldade em se definir o que é a saúde, dizendo que definir a saúde pelo seu oposto, ou seja, ausência de doença, embora tentador, é algo circular e incompleto. É como definir um gato por não ser um cachorro ou como dizer que alguém baleado não está saudável, ainda que este evento não caracterize doença. Finalmente, o escritor comenta sobre a definição de saúde como o "silêncio dos órgãos", também problemática, proposta no século XIX. Essa definição é contrastada pelo "silêncio" do sistema imunológico quando um indivíduo é infectado pelo vírus HIV, por exemplo. Nesta situação, o "silêncio" é uma ausência de expressão clínica de uma batalha travada entre o vírus e as células de defesa infectadas, caracterizando, assim, uma expressão (silenciosa) da doença. O capítulo trata ainda da definição da Organização Mundial da Saúde - "saúde como completo bem-estar" - inaplicável ao mundo real. Apesar dos contrastes apresentados, o leitor não se sente frustrado, pois o autor faz uma analogia do amor com a saúde: difícil de definir, mas fácil de sentir.

A partir das ideias propostas no capítulo primeiro, o segundo ("O mundo do muito pequeno") aborda a composição do que existe no mundo - átomos e moléculas -, buscando entender por que o "muito pequeno", embora não diga respeito à vida e à saúde (o autor problematiza o tema), interfere na constituição do que é o nosso "eu". Os elementos são importantes porque não conseguimos sintetizá-los. Cita os exemplos dos oligoelementos, destacando o papel do zinco e do flúor. Assim, Bastos consegue traduzir um tema complexo em algo muito próximo do cotidiano do leitor, tais como os complexos vitamínicos.

Em sequência lógica, o terceiro capítulo cresce em dimensão (" $O$ mundo do pequeno”). Após explicar o que é homeostase, ATP, catálise e substratos e o ácido lático (chamando atenção para atividade física após um período de inatividade), os conceitos fluem bastante bem e é aí que se começa a entender o porquê das alergias, da Aids e porquê, se há indivíduos vivos, é devido ao sistema imunológico ter permitido. Ainda neste capítulo, o autor afirma que genoma não é algo vivo e sim um roteiro, que orienta as células, traçando um paralelo entre uma planta de arquitetura e uma construção. Explicita que, se o código genético de um alimento é modificado (os transgênicos), o organismo vivo pode não "entender" a nova mensagem e surgirão as alergias. Sem fazer alarde, mas deixando claras 
as implicações da engenharia genética, Bastos afirma que "é preciso ter alguma paciência com os transgênicos".

"Do meu e do seu tamanho" é o capítulo seguinte e trata do que está ao nosso alcance ou ao nosso plano de visão, como os exames para diagnóstico, as doenças transmissíveis e infecciosas e sua propagação, os surtos epidemiológicos e as doenças transmitidas por alimentos contaminados. O que há de inovador neste capítulo é a abordagem que se inicia no indivíduo e no seu significado - indivisível - e se alastra pelo conceito de rede social. Rede social, na saúde, atua permitindo a propagação de doenças e hábitos - tanto local quanto global. Os exemplos de disseminação que autor aborda são o vírus da Aids, a obesidade e a criminalidade.

Se no capítulo quarto a ideia eram as pessoas perto de nós, atuando em nossas vidas por meio de contatos diretos, ou simplesmente compartilhando vetores ou hábitos comuns, o capítulo seguinte aborda o que é a Saúde Pública, ou seja, o que é "maior que eu". As passagens são sempre pautadas pelas definições (o que é saúde pública, prevalência e estigma, por exemplo). Bem elaborada é a ideia do que (não) é o racismo e, finalmente, do que são o estigma social e a discriminação. O capítulo é inquietante e o autor deixa claro: "as vítimas de discriminação se sentem sós, tristes e desmotivadas". E isso afeta a saúde.

O capítulo sexto trata do planeta Terra, e de temas como fotossíntese, raios ultravioletas, câncer de pele, raquitismo, avançando em questôes atuais e preocupantes, como o buraco na camada de ozônio e o aquecimento global. Enfim, refere-se a algo "bem maior do que eu". Bastos cita desastres ecológicos e comenta, sem grande assombro e sem assustar o leitor (ele não se considera um pessimista), os efeitos de curto e longo prazo na saúde das pessoas. Segundo o autor: "estamos no fim das contas forçando a velha Terra a nos mandar mais cedo para o vestiário".

"Afinal, o que é saúde" é o título do sétimo capítulo, que vem somar os elementos trazidos nos capítulos anteriores, levando o leitor não a uma definição estanque, mas ao seu próprio entendimento do que é saúde. O que não é difícil, pois tudo o que é necessário para esta concepção ficou bem explicado ao longo dos capítulos anteriores. A ideia de que a saúde é uma construção harmônica e organizada emerge naturalmente. 
Ao final da leitura, percebe-se que o autor seguiu uma linha de raciocínio e ordenamento lógico criativos, abordando temas que vão desde as partículas subatômicas até as estrelas. Ao percorrer os mundos que variam do muito pequeno ao muito grande, Bastos faz um passeio pela Inglaterra da Revolução Industrial, o porto de Minamata, no Japão, poluído por causa do mercúrio, até o espaço sideral, registrando os efeitos da ausência de gravidade no corpo dos astronautas. Em uma abordagem ampla, chegou até mesmo diferenciar símios (apes, em inglês) de macacos (monkeys). Por outro lado, em alguns pontos, o autor mostrou-se repetitivo, como no caso das bombas americanas lançadas sobre Hiroshima e Nagasaki.

Necessário registrar ainda que o escritor deixou de mencionar alguns nomes importantes da História, principalmente no quarto capítulo, onde trata das infecções. Por exemplo: poderia ter informado ao leitor sobre o papel de pessoas como a enfermeira britânica Florence Nightingale, que durante a guerra da Crimeia, constatou que a falta de higiene no tratamento de feridos provocava doenças tão ou mais letais aos soldados que as próprias feridas, advocando, assim, mudanças que salvaram muitas vidas. Também esteve ausente a contribuição pioneira do médico Ignaz Phillip Semmelweiss, que observou a transmissão de doenças nos hospitais causada pela falta de esterilização dos equipamentos cirúrgicos e de assepsia pelos médicos, por não seguirem atos simples como desinfetar as mãos.

A obra seria enriquecida se, nesse mesmo capítulo, houvesse menção da batalha de anos entre os defensores de que a transmissão de doenças acontecia através de micróbios, como John Snow, contra os que defendiam a teoria dos miasmas, dentre os quais estava Edwin Chadwick, e que levou muito tempo para ser refutada. Os miasmistas defendiam que doenças como a cólera eram causadas por mau cheiro ou miasma. Tal crença está relacionada a milhares de mortes por cólera em Londres e Paris, afetando até mesmo o Rio de Janeiro nos tempos do sanitarista Oswaldo Cruz.

A descoberta dos antibióticos, ocorrida por acaso, como a penicilina, pelo médico escocês Alexander Fleming, é também uma ausência sentida na obra. Outra ausência decorre do fato de o autor, embora tenha feito observaçôes 
importantes sobre elementos como o zinco e flúor no segundo capítulo, não se ter dedicado ao sódio (cloreto de sódio), cujo papel no funcionamento do organismo é imprescindível.

Apesar de algumas lacunas, até mesmo esperadas pela abrangência de temas contemplados na obra, o livro pode e deve ser utilizado como material auxiliar aos estudantes do ensino médio, como o próprio autor sugere. Contudo, o papel da obra é muito maior. É um convite a todos, não apenas estudantes, a atualizarem seus conceitos de vida e de saúde por intermédio de uma perspectiva integrada e sequencial, que vai do muito pequeno ao muito grande, com notável fluidez, tornando a leitura leve e agradável. ${ }^{1}$

\section{Nota}

${ }^{1}$ As autoras participaram igualmente de todas as etapas de elaboração desta resenha. 